\title{
Performance Comparison of Different Models of Direct Steam Solar Plants Based on Parabolic Trough Technology by Simulink MATLAB
}

\author{
Sanan T. Mohammad ${ }^{1}$, Hussain H. Al-Kayiem ${ }^{1 *}$, Syed I. U. Gilani ${ }^{1}$ and Ayad K. Khlief ${ }^{1}$ \\ ${ }^{1}$ Mechanical Engineering Department, Universiti Teknologi PETRONAS, 32610 Bandar Seri \\ Iskandar, Perak, Malaysia
}

\begin{abstract}
Solar thermal plants are among the most promising technologies to replace fossil fuel standing applications. Among solar thermal technologies, parabolic troughs are considered as the most mature application in the market. The objective of this paper is to elaborate on comparison results of three different topologies of solar parabolic troughs field, in terms of performances and energy production. Thermolib software was used to perform the proposed power plants simulation with direct steam generation. Applying the proposed models. These models simulate the behaviour of both the solar field and the power block of a $1.2 \mathrm{~kW}$ solar thermal power plant. The results of this analysis demonstrating that the use of steam separator and superheater in a stand-alone solar power plant model is more advantageous in terms of steam temperature, steam quality and net electricity production in comparison to other models. The optimum topology showed that the maximum temperature of steam outlet reach $221^{\circ} \mathrm{C}$, steam quality reach 1 and efficiency of power plant around $19.6 \%$ for model 3 .
\end{abstract}

\section{Introduction}

In the 21 st century, there are many problems that raise in perspective of energy and environment; thus, leading to a rising problems in politics and economy. A study stated that for a sustainable supply of energy and a reduction in emissions of the pollutants, there is an intense focus on renewable energy in the world $[1,2]$. Another study thoroughly discusses the parabolic trough solar thermal power plants (PTSTPP) in terms of their potentials and developments in Algeria. The authors emphasized that the process of working principles, descriptive parabolic trough power plants, and an assessment of concentrating solar power (CSP) potential has provided a competitive outcome in terms of viability of CSP plants in Algeria. In addition to that, Algeria needs to consider the pre-requisites such as high-quality insolation, land and water availability, extensive transmission, and the power grid; to provide an economical CSP power generation [3, 4]. However, [5] studied carried out in Algeria where the authors tested on Optimization, Selection, and feasibility study of solar parabolic trough power plants.

\footnotetext{
* Corresponding author: hussain kayiem@utp.edu.my
} 
Optimization of the two parabolic trough was integrated and performed with: 1) thermal energy storage TES, and 2) fuel backup system FBS, respectively. The heat fluid used by 1st plant was Therminol VP-1 in field and 2nd plant used molten salt. In relation to that, [6] developed a simulation model that allows a recalculation of performance of $50 \mathrm{MWe}$ parabolic trough power plant; which is accompanied with thermal energy storage whilst Therminol VP-1 as heat transfer fluid in the solar field. The results obtained from the model are compared with the experimental data which was obtained from operation power plants in Spain. [7] highlighted influences of solar multiple annual performance, natural gas consumption, and Levelized cost of electricity of a $50 \mathrm{MWe}$; using direct steam generation parabolic trough thermal power plant with thermal storage and auxiliary natural gas-fired boiler. A study presents a thermodynamic model which allowed an estimation of performance of $100 \mathrm{MW}$ hybrid parabolic trough solar thermal power plant; whilst fossil fuels backup friction required. As it was conducted in four location North Chile); it was based on minimal fossil fuel backup fraction [8]. Moreover, another author used 50MW solar thermal power plant and requirement of the land area with parabolic trough system integration; and suggests this technology as the best to its industrial advantages [9]. A study analysed an energetic economic assessment of a solar parabolic trough power plant of $100 \mathrm{MW}$ capacitate and discussed amongst the four sites chosen in Algeria [10]. On the other hand, a study discusses on the technical developments of the parabolic trough solar power plant when combined with molten salt as HTF, and presents the potential of using this technology to reduced LCOE [11]. Typically, this feasibility report was combined with optimization results, where 4E comparison of PTSTPPs with molten salt is primary HTFs was established in solar field. The results obtained were agreed upon by [12]; where presentation of a theoretical framework for energy and exergy analyses of a solar power tower plant whilst incorporating solar molten salt as HTF. Similarly, this analysis was also conducted in another research which accounts for parabolic trough solar thermal power plant using therminol VP-1 as working fluid [13]. In order to optimize and obtain the maximum plant efficiency, the authors evaluated the energetic and exegetic losses and efficiencies through specified operating conditions.

As literature conclusion, it is revealed that the technical disability of PTSTPP is yet to be established for a location that has a high DNI availability. There is also a need to identify the CSP technology for Malaysia climatic condition. The aim of this paper is to compare three different models of Stand-alone PTSTPP with an average capacity of $1.2 \mathrm{~kW}$. Universiti Teknologi PETRONAS, Perak, Malaysia has been selected as the location of operation. Theoretical calculations have been carried out in MATLAB software. The results of the calculations are employed in this software as inputs/parameters in order to model \& simulate the performance of the stand-alone parabolic trough solar power plant in Simulink ${ }^{\circledR}$ Thermolib software, effectively.

\section{Models and simulation}

The simulation model duplicates the thermal and hydraulic behavior of each component of the plant including the main elements of the solar field and the power block. The model has been developed with the Thermolib software tool a graphically-based environment used to simulate transient systems. Models are created by connecting different components, providing a flexible tool that allows different configurations and sizes of the plant and an easy modification of details such as collector type, location, etc. This study presents the three models cooperation in this paper. For all cases, considered a design power output of the solar plant of $1.2 \mathrm{~kW}$. The first model is based on steam separator without superheater; the second is a stand-alone power plant without steam separator and superheater; the last one model is based on steam separator and super- heater. The size of the solar power generation plant using 
a parabolic trough collector field is selected to be $1.2 \mathrm{~kW}$. Figure 1 illustrates the proposed three models solar power plant established.

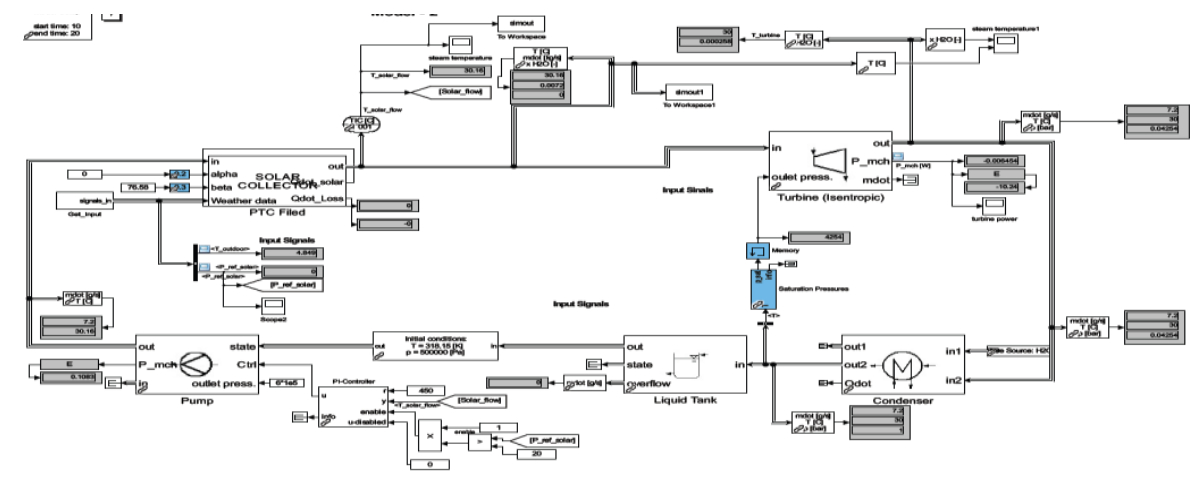

a) Model I: Stand-alone parabolic without steam separator and superheater trough power plant

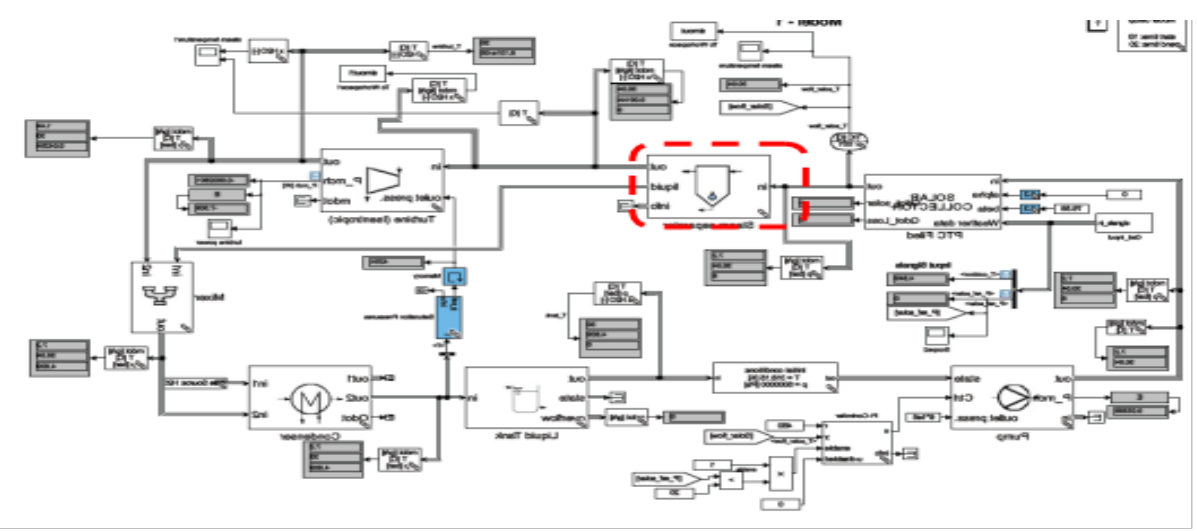

b) Model II: Stand-alone parabolic with steam separator without superheater trough power plant.

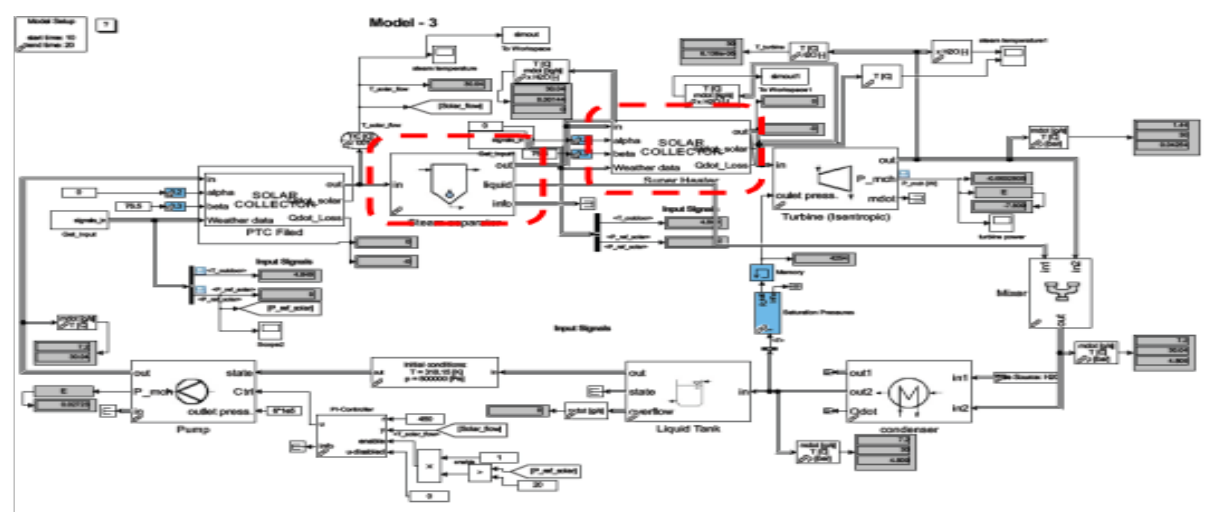

b) Model III Stand-alone parabolic with steam separator with superheater trough power plant.

Fig. 1. Simplified process flow diagram a PTC based solar thermal power plant. 


\section{Result and discussion}

In the study, only one day is presented with the data collected, the performance of the system is observed through the evaluation of the results that are provided by the simulation models in the study. With the assistance of the model, it is able to provide valuable data which is capable of plotting graphs, such as: 1) Solar radiation, 2) steam temperature leaving the collector field, 3) exit steam quality and 4) the power output of the system. With that, there were a few system parameters which were kept constant: (1) water mass flow rate and steam's mass flows, (2) number of collectors, (3) water inlet temperature, (4) condensate water temperature and pressure and (5) the turbines' operating pressure. The SEGs was used to monitor these parameters carefully. Thus, providing a means of system control. PTC specifications and their characteristics that are considered throughout the system monitoring are shown in Table1.

Table 1. Characteristics of PTC used for simulation

\begin{tabular}{|l|c|}
\hline \multicolumn{1}{|c|}{ Parameters } & Value \\
\hline Length of the receiver (L) & $6.4 \mathrm{~m}$ \\
\hline Width of the collector ( $\left.\mathrm{W}_{\mathrm{a}}\right)$ & $2.6 \mathrm{~m}$ \\
\hline Focal length (F) & $0.87 \mathrm{~m}$ \\
\hline Receiver external diameter (Dao) & $40 \mathrm{~mm}$ \\
\hline Receiver internal diameter (Dai) & $38 \mathrm{~mm}$ \\
\hline
\end{tabular}

Figure 2 shows results obtained on a clear sunny day, thus, more radiation and an optimal system performance is observed, respectively. However, when solar transients due to clouds occur, it shows an overall drop in system temperature. Hence, the power output drops. If the occurrence of these transient is for a period of 5 to 10 minutes' intervals, then the system is able to return to its steady power production state as the solar radiation is maintained. However, if the solar transients are prolonged (an hour or more); then the system performance is gradually reduced in a great amount and a possibility of system recovery is merely present.

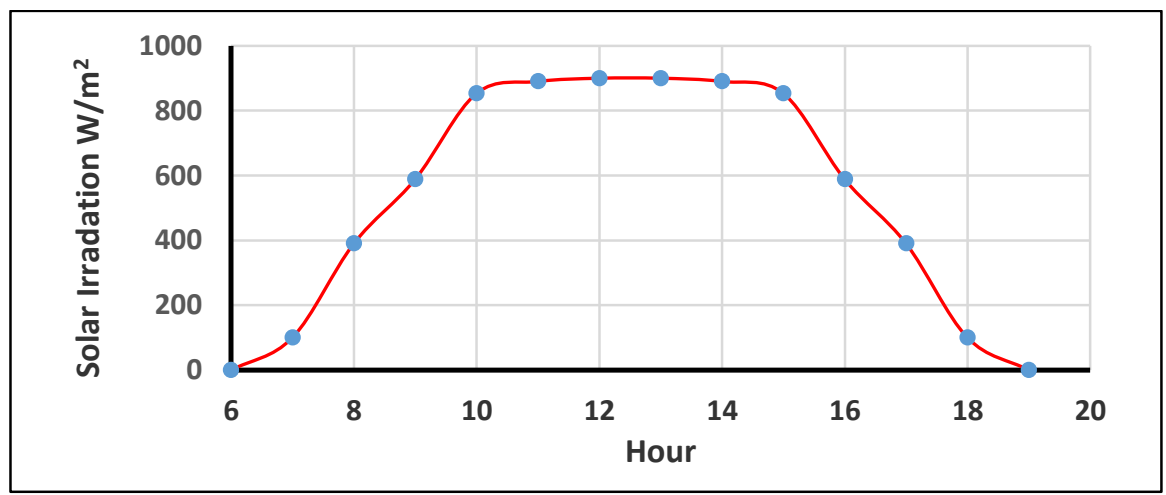

Fig. 2 Direct solar irradiance vs. solar hour.

Figure 3 shows that the outlet temperature of the solar field is very similar for both model 1 and model 2. Nonetheless, the maximum temperature registered around $158{ }^{\circ} \mathrm{C}$ for both models. For regarding model 3 as shown in fig 3 temperature of steam outlet reach $221{ }^{\circ} \mathrm{C}$ at $12 \mathrm{pm}$ due to superheater in this model. Superheater part assist to increase outlet temperature steam. 


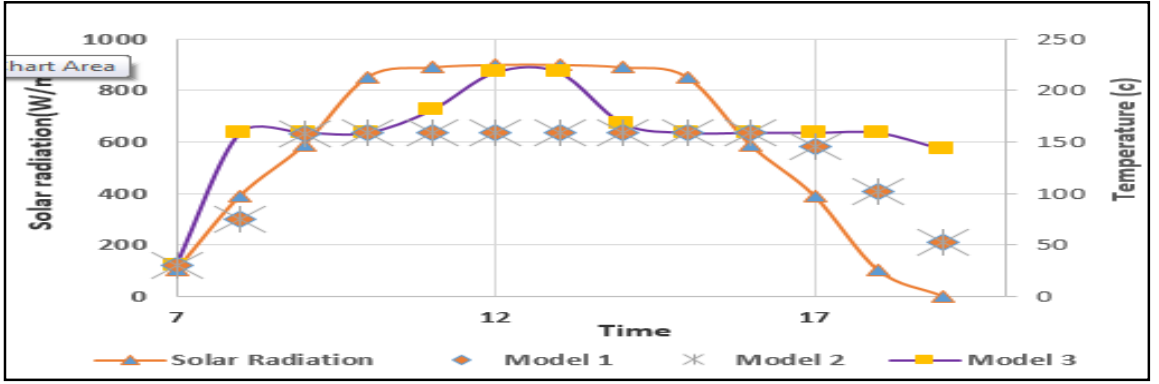

Fig. 3. Hourly collectors useful heat gain during the year.

An analysis of the daily power output, DNI and the efficiency for the Universiti Teknologi PETRONAS location was carried out. Figure 4 shows the gross electrical power output at chosen one day. It was clearly observed that the gross output of the plant was maximum at higher in model 2 around $1200 \mathrm{~W}$ because not has steam separator, which leads to the maximum mass flow rate of steam enter to turbine and thus the production maximum power electric. The power output is directly proportional to the increase in the amount of steam entering the turbine. Power output is very similar for both model 1 and model 3 due to the amount of steam entering the turbine be equal. Nonetheless, the maximum power output registered is around $1000 \mathrm{~W}$ for both models.

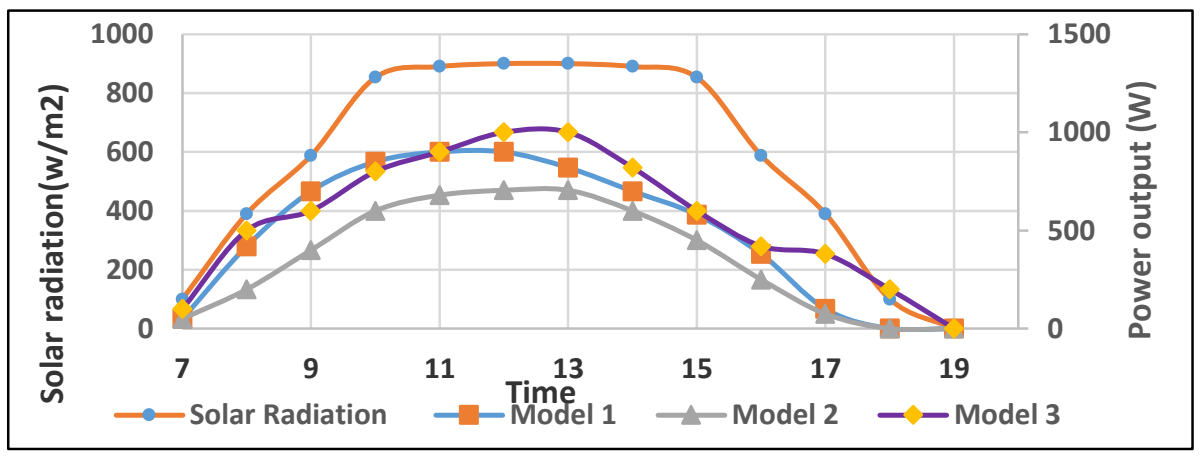

Fig. 4. The daily efficiency for the Universiti Teknologi PETRONAS location in the year.

Figures 5 presents the average of hourly efficiency from parabolic trough solar power plant of two days. It was clearly observed that the efficiency of the plant was maximum at higher in model 3. It is seen that the DNI is relatively higher in the month of February and June is resulting in higher efficiency of power plant around $19.6 \%$ at $12 \mathrm{pm}$.

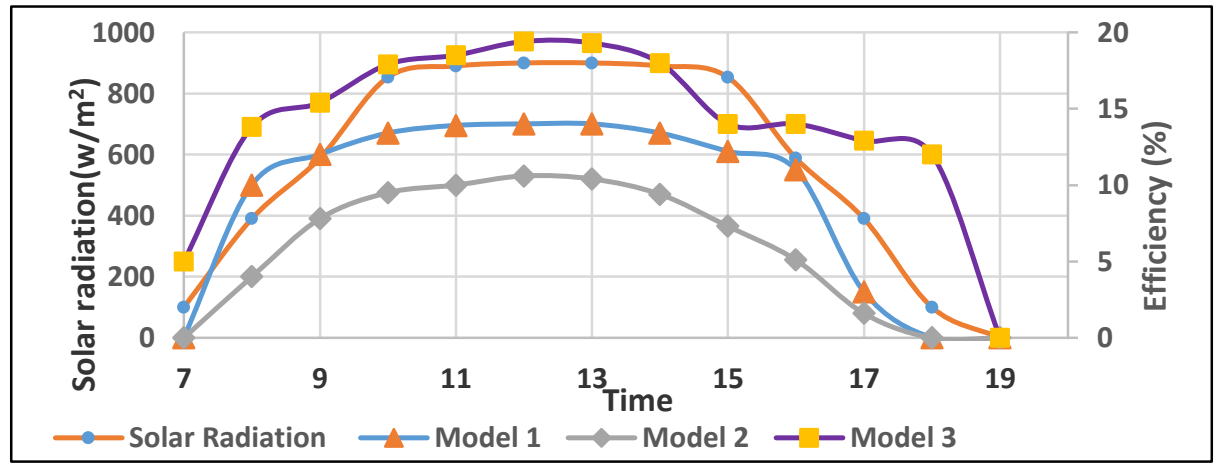

Fig. 5. Solar radiation and efficiency of system for sunny day 


\section{Conclusion}

This paper presented a detailed comparison among three different models solar plants based on parabolic trough technology. Results indicate relevant differences among the energy performance of the solutions considered: outlet temperature steam, steam quality and the net output power between models. The preliminary analysis of the steam temperature and quality at conditions yield a better performance of Model 3 with respect to the models case. Moreover, according to the results of the simulation the use of steam separator and superheater in DSG solar plants not only would allow a higher efficiency of the power block, but also would be able to provide a better solar field performance, involving a higher amount of useful thermal energy. As a consequence, the differences in terms of annual net electricity suggest that Model 3 is a good way to improve the performance of DSG plants.

The authors acknowledge Universiti Teknologi PETRONAS for the financial support to conduct the research work. Also, appreciations are due to Ministry of Higher Education MOHE - Malaysia for utilizing FRGS/1/2015/TK10/UTP/03/2 under CS: $0153 \mathrm{AB}-\mathrm{K} 81$ to support the publication of the research results in this paper.

\section{References}

1. E. Xu, D. Zhao, H. Xu, S. Li, Z. Zhang, Z. Wang, Energy Procedia, 69, $1471-1478$ (2015).

2. A. K. Khlief, S. I.U. Gilani1, H. H. Al-Kayiem, S. T. Mohammad, MATEC Web of Conferences 131, 02002 (2017).

3. S. T. Mohammad, H. H. Al-Kayiem, M. K. Assadi, O. Sabir, A. K. Khlief, Case Studies in Thermal Engineering 12, 26-37(2018).

4. S. T. Mohammad, H. H. Al-Kayiem, M. K. Assadi, S. I. U. Gilani, A. K. Khlief, MATEC Web of Conferences 131, 02008 (2017).

5. T.E. Boukelia, et al., Energy Convers. Manag. 101, 450-459 (2015).

6. L. I. García, J. L. Álvarez, D. Blanco, Sol. Energy 85 (10), 2443-2460 (2011).

7. M.J. Montes, A. Abànades, J. M. Martınez-Val, Sol. Energy 83(5), 679-689 (2009).

8. T. Larraín, R. Escobar, J. Vergara, Renew Energy 35(8), 1632-1643 (2010).

9. S.A. Kalogirou, Renew. Energy 49, 278-281(2013).

10. M. Abbas, Z. Belgroun, H. Aburidah, N. K. Merzouk, Energy Procedia 42, 93102(2013).

11. T. Ruegamer, H. Kamp, T. Kuckelkorn, W. Schiel, G. Weinrebe, P. Nava, et al., Energy Procedia 49, 1523-1532 (2014).

12. C. Xu, Z. Wang, X. Li, F. Sun, Appl. Therm. Eng. 31(17), 3904-3913 (2011).

13. V.S. Reddy, S.C. Kaushik, S.K. Tyagi, Energy 39 (1), 258-273(2012). 